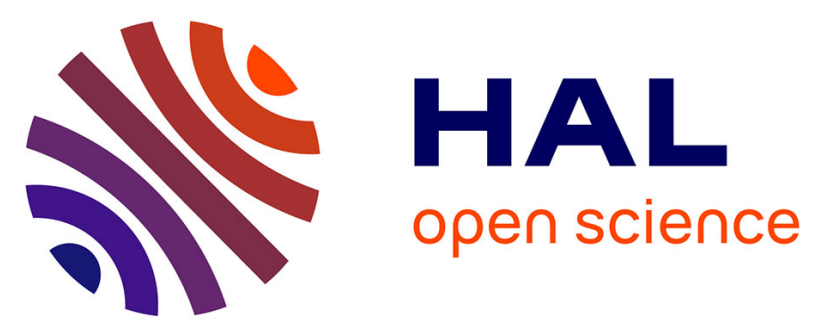

\title{
Multiple and antagonistic effects of water on intrinsic physical properties of model Fischer-Tropsch cobalt catalysts evidenced with in situ X-ray diffraction.
} Julien Scalbert, Christèle Legens, I. Clemencon, Anne-Lise Taleb, Loïc Sorbier, Fabrice Diehl

\section{To cite this version:}

Julien Scalbert, Christèle Legens, I. Clemencon, Anne-Lise Taleb, Loïc Sorbier, et al.. Multiple and antagonistic effects of water on intrinsic physical properties of model Fischer-Tropsch cobalt catalysts evidenced with in situ X-ray diffraction.. Chemical Communications, 2014, 50 (58), pp.7866-7869. 10.1039/c4cc00947a . hal-01053703

\section{HAL Id: hal-01053703 \\ https://hal-ifp.archives-ouvertes.fr/hal-01053703}

Submitted on 1 Aug 2014

HAL is a multi-disciplinary open access archive for the deposit and dissemination of scientific research documents, whether they are published or not. The documents may come from teaching and research institutions in France or abroad, or from public or private research centers.
L'archive ouverte pluridisciplinaire HAL, est destinée au dépôt et à la diffusion de documents scientifiques de niveau recherche, publiés ou non, émanant des établissements d'enseignement et de recherche français ou étrangers, des laboratoires publics ou privés. 


\section{Multiple and antagonistic effects of water on intrinsic physical properties of model Fischer- Tropsch cobalt catalysts evidenced by in situ $\mathrm{X}$-ray diffraction $\dagger$}

Cite this: Chem. Commun., 2014 50,7866

Received 5th February 2014 Accepted 30th May 2014

DOI: $10.1039 /$ c4cc00947a

www.rsc.org/chemcomm

\author{
J. Scalbert, * C. Legens,* I. Clémençon, A.-L. Taleb, L. Sorbier and F. Diehl
}

Direct evidence for cobalt oxidation under water treatment at $230{ }^{\circ} \mathrm{C}$ was revealed using in situ XRD, even in the presence of small amounts of $\mathrm{H}_{2}$. Oxidation kinetics was proved to be particle size dependent. The resulting $\mathrm{CO}_{3} \mathrm{O}_{4}$ showed a firmly smaller coherent domain size than the initial calcined catalyst.

Fischer-Tropsch synthesis allows converting synthesis gas into hydrocarbons and water. High-quality fuels such as diesel and kerosene can be produced from this catalytic reaction. Considering the irrecoverable decrease in petroleum resources and the continuous need for transportation fuels, the Fischer-Tropsch process gets even more attention as especially the syngas reactant can be obtained from various sources such as biomass, coal or natural gas. Because of their efficiency in the production of high molecular weight $n$-alkanes, supported cobalt catalysts are widely used in industry. ${ }^{1}$

Origins of catalyst deactivation with time on stream are still unclear and thought to be a combination of various phenomena such as carbon deposition, poisoning, oxidation and sintering. ${ }^{2,3}$

Water is the major product in the Fischer-Tropsch reaction and its effects on catalytic properties are still widely discussed. Recently, Bezemer and coworkers ${ }^{4}$ showed that water was not able to oxidize carbon nanofiber supported cobalt catalysts during Fischer-Tropsch synthesis but was responsible for enhanced sintering of cobalt. However, they also indicated that oxidation of cobalt to $\mathrm{CoO}$ did take place in the absence of hydrogen.

To investigate the effects of water on the structural properties of well-defined Fischer-Tropsch Co/silica model catalysts, in situ XRD experiments were carried out at $230{ }^{\circ} \mathrm{C}, 1$ bar, under a $0-0.5 \% \mathrm{H}_{2} /$ $1-2.3 \% \mathrm{H}_{2} \mathrm{O} / \mathrm{He}$ flow. Water vapour was introduced in the system by flowing He vector gas through a saturator containing liquid water kept at constant temperature. The morphological changes of

IFP Energies nouvelles, Rond-point de l'échangeur de Solaize, BP 3, 69360 Solaize, France.E-mail: julien.scalbert@ifpen.fr, christele.legens@ifpen.fr

$\dagger$ Electronic supplementary information (ESI) available: Particle size distributions determined by TEM before and after water treatment and quantification of crystalline phases using XRD. See DOI: 10.1039/c4cc00947a the catalysts were also studied using transmission electron microscopy (TEM) and scanning electron microscopy (SEM).

These chosen experimental conditions are not typical Fischer-Tropsch conditions $\left(200-230{ }^{\circ} \mathrm{C}\right.$, high pressure, CO conversion around $50-70 \%$ ) but the unexpected results obtained with this very low water content showed multiple effects on $\mathrm{Co} /$ silica physical properties, which could be useful in further understanding the deactivation phenomena of cobalt catalysts during Fischer-Tropsch synthesis.

$\mathrm{Co} /$ silica catalysts with a metal loading of $13 \mathrm{wt} \%$ were synthesized by $\mathrm{Co}\left(\mathrm{NO}_{3}\right)_{2}$ incipient wetness impregnation on silica (DAVISIL ${ }^{\circledR}$ grade 634 calcined at $900{ }^{\circ} \mathrm{C}$ prior to impregnation) with various quantities of ethylene glycol to get catalysts with different cobalt particle sizes. ${ }^{5}$ After calcination at $400{ }^{\circ} \mathrm{C}$, the $\mathrm{Co}_{3} \mathrm{O}_{4}$ average crystallite size of the resulting $7 \mathrm{~nm}-\mathrm{Co} /$ silica and $12 \mathrm{~nm}-\mathrm{Co} /$ silica catalysts was 7.0 and $12.2 \mathrm{~nm}$, respectively, as determined by the Scherrer equation on the X-ray diagram. These values were confirmed by dark field TEM measurements which also indicated particle size distributions (see ESI, $\dagger$ Fig. S1).

In situ measurements were carried out using $\mathrm{Cu}(\mathrm{K} \alpha)$ radiation on a Panalytical diffractometer equipped with an Anton Paar XRK 900 reaction chamber. Before steam treatment, the samples were first reduced under pure $\mathrm{H}_{2}$ up to $700{ }^{\circ} \mathrm{C}$ so that facecentred cubic (fcc) $\mathrm{Co}^{0}$ was the main crystallographic phase. The reactor was then cooled at $230{ }^{\circ} \mathrm{C}$ under He and a reference XRD pattern recorded before steam treatment. The reference X-ray diagram allowed us to identify and quantify the crystalline phases after reduction: the $7 \mathrm{~nm}-\mathrm{Co} /$ silica sample consisted of around $85 \%$ Co (fcc) and 15\% remaining $\mathrm{CoO}$, whereas the $12 \mathrm{~nm}-\mathrm{Co} /$ silica sample was almost fully reduced. No sintering of the metallic phase was observed during the reduction step.

A first water treatment on these catalysts was carried out at $230{ }^{\circ} \mathrm{C}$ for 5 days under a $1 \% \mathrm{H}_{2} \mathrm{O} / \mathrm{He}$ flow and XRD patterns were simultaneously recorded. In both cases, X-ray diagrams show slow oxidation of metal cobalt to $\mathrm{CoO}$ (first oxidation product) and then to $\mathrm{Co}_{3} \mathrm{O}_{4}$ (second oxidation product) (Fig. 1).

Even after 70-110 hours on stream, $\mathrm{Co}_{3} \mathrm{O}_{4}$ is the only observed crystalline phase. This unambiguously evidences that the full 


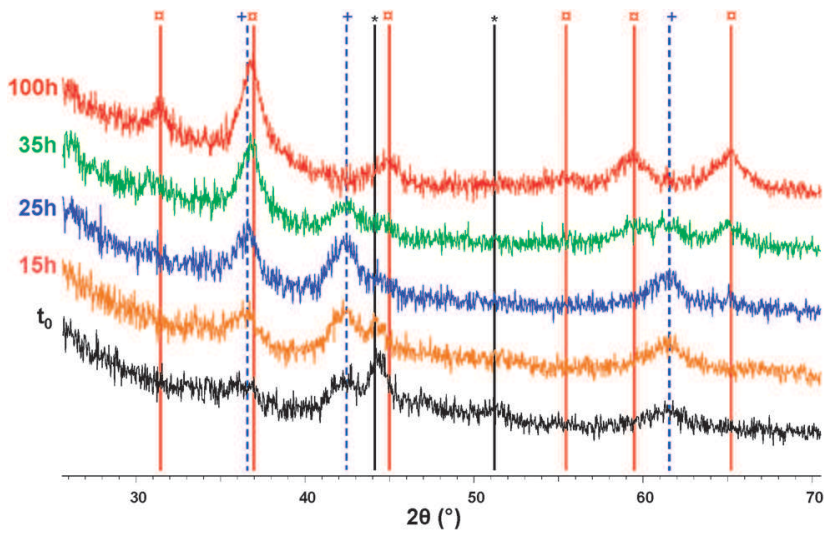

Fig. 1 In situ XRD patterns of $7 \mathrm{~nm}-\mathrm{Co} / \mathrm{SiO}_{2}$ during treatment under $1 \% \mathrm{H}_{2} \mathrm{O} / \mathrm{He}$ at $230{ }^{\circ} \mathrm{C}$ for different time on stream. Symbols: ${ }^{*} \mathrm{Co}$ (fcc); + $\mathrm{CoO} ; \square \mathrm{CO}_{3} \mathrm{O}_{4}$.
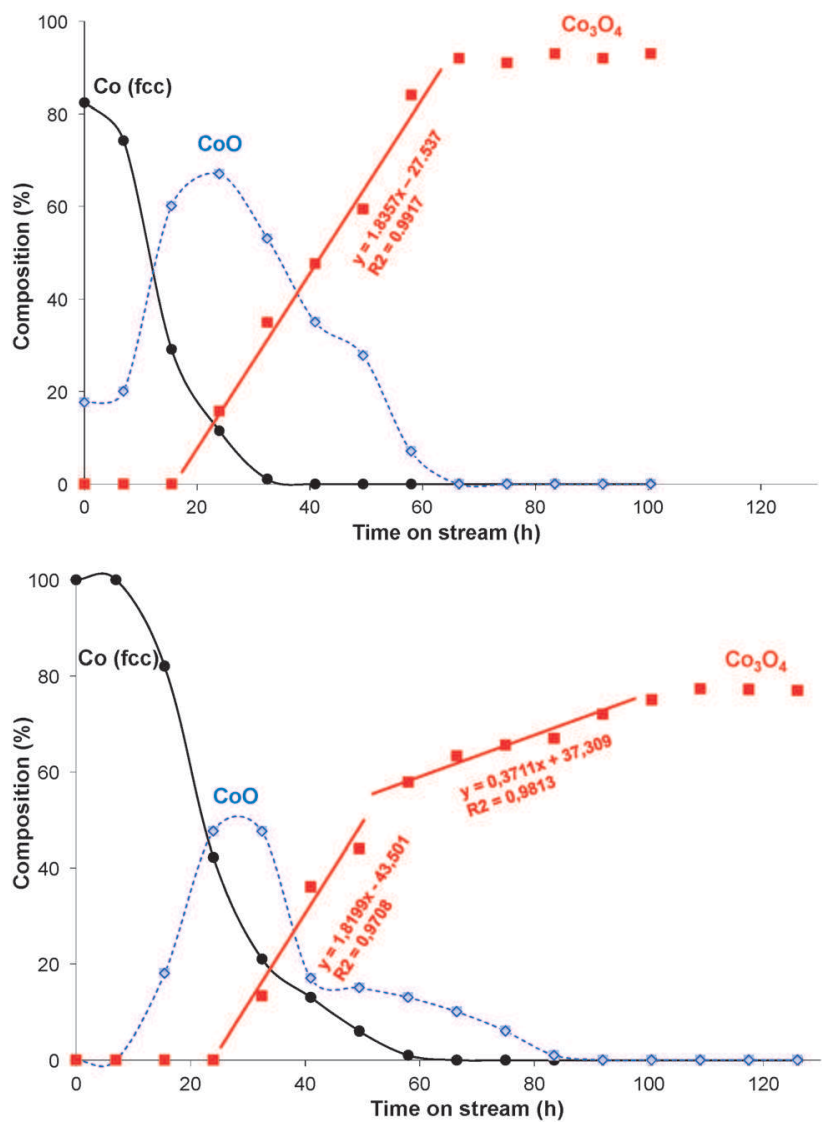

Fig. 2 Composition as a function of time on stream under $1 \% \mathrm{H}_{2} / \mathrm{He}$ at $230{ }^{\circ} \mathrm{C}$ of the $7 \mathrm{~nm}$-Co/silica (top) and $12 \mathrm{~nm}$-Co/silica (bottom) catalysts.

oxidation of cobalt to its highest oxidation state counterpart $\mathrm{Co}_{3} \mathrm{O}_{4}$ is possible, at $230{ }^{\circ} \mathrm{C}$, even at very low water partial pressure, i.e. 0.01 bar. This supports and complements the pioneering studies of Schanke et $a l^{6}{ }^{6}$ and van Berge et al. ${ }^{7}$ showing partial oxidation of $\mathrm{Co} /$ $\mathrm{Al}_{2} \mathrm{O}_{3}$ catalysts during treatments with water.

Quantification of crystalline phases (details in ESI $\dagger$ ) allowed monitoring the evolution of the composition with time on stream, and subsequently the kinetics of cobalt oxidation (Fig. 2).
In both cases, $\mathrm{Co}_{3} \mathrm{O}_{4}$ formation was observed to begin approximately when the $\mathrm{CoO}$ content was maximum, which seems to confirm that $\mathrm{Co}_{3} \mathrm{O}_{4}$ is formed from the $\mathrm{CoO}$ intermediate and not directly from Co as it could appear in the cases of harder oxidation treatments under oxygen. ${ }^{8}$

In the case of the $7 \mathrm{~nm}-\mathrm{Co} /$ silica sample, $\mathrm{Co}_{3} \mathrm{O}_{4}$ gradually forms between 18 and 65 hours on stream, the kinetics of formation following a linear slope. In the case of the $12 \mathrm{~nm}$-Co/silica sample, $\mathrm{Co}_{3} \mathrm{O}_{4}$ formation begins later, after 22 hours on stream. This may be due to the fact that this catalyst was previously fully reduced, contrary to the $7 \mathrm{~nm}-\mathrm{Co} / \mathrm{silica}$ sample in which some $\mathrm{CoO}$ was still present at the beginning of the steam treatment.

Contrary to the $7 \mathrm{~nm}-\mathrm{Co} /$ silica, the formation of $\mathrm{Co}_{3} \mathrm{O}_{4}$ from the $12 \mathrm{~nm}-\mathrm{Co} /$ silica catalyst clearly follows two different kinetics (two apparent slopes in Fig. 2). In a first time, between 22 and 60 hours on stream, the rate of $\mathrm{Co}_{3} \mathrm{O}_{4}$ formation is similar to that of $7 \mathrm{~nm}-\mathrm{Co} /$ silica, whereas in a second period, between 60 and 110 hours on stream, the $\mathrm{Co}_{3} \mathrm{O}_{4}$ formation follows a much slower rate.

Considering the size distribution of each catalyst (Fig. S1, ESI $\dagger$ ), one could assign these two kinetics to the oxidation of particles of different size. This means that small particles are more easily and more quickly oxidized by water than bigger particles. This could be explained by the contribution of the surface energy of Co nanoparticles to the oxidation process. ${ }^{9}$ Considering this feature, catalysts with bigger cobalt particles should be preferred for Fischer-Tropsch synthesis in order to prevent oxidation by in situ formed-water which could be a cause of deactivation as already suggested by several authors. ${ }^{3}$

Besides the oxidation phenomenon, it is worth noting that the XRD patterns are not identical before the reduction of the samples and after the steam treatment, although $\mathrm{Co}_{3} \mathrm{O}_{4}$ is in both cases the only observable crystalline phase (Fig. 3).

The area of each peak is much lower after treatment than before reduction. This unexpected observation clearly means that some cobalt species are not detected anymore by the X-ray diffraction technique, most likely because their size is below the detection limit of around $2 \mathrm{~nm}$. This means that some cobalt particles crumbled during steam treatment. No background broadening was observed on XRD patterns, thus providing the information that no amorphous phase was formed during the process.

The coherent domain size of the observable particles was determined by the Scherrer equation with the full width at half maximum (FWHM) of the most intense peak of $\mathrm{Co}_{3} \mathrm{O}_{4}$.

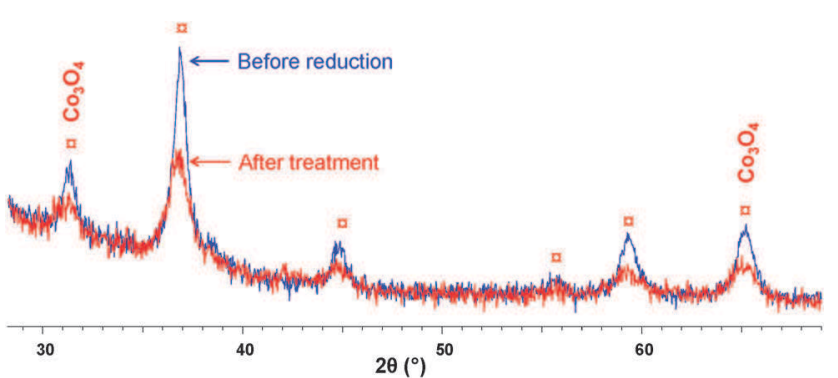

Fig. 3 XRD patterns of the $12 \mathrm{~nm}-\mathrm{Co} /$ silica catalyst before reduction and after treatment. 


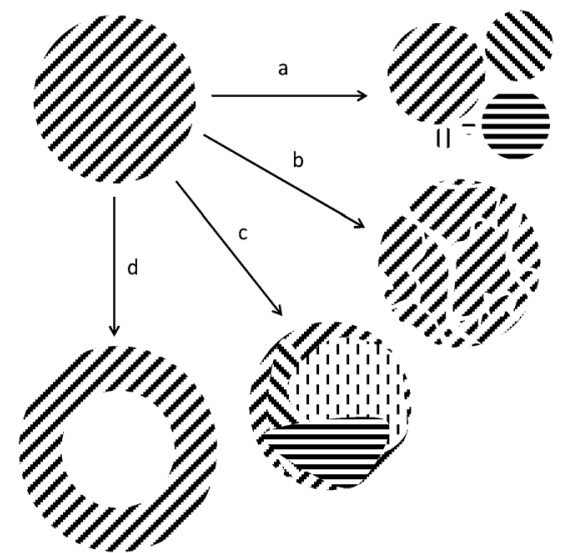

Scheme 1 Possible physical changes in cobalt particles during steam treatment at $230{ }^{\circ} \mathrm{C}$; (a) partition, (b) crumbling, (c) crystalline geometry change, (d) Kirkendall effect.

After treatment, the apparent size of $\mathrm{Co}_{3} \mathrm{O}_{4}$ was about $7.4 \mathrm{~nm}$ in the case of the $12 \mathrm{~nm}-\mathrm{Co} /$ silica catalyst, whereas it was $12.2 \mathrm{~nm}$ initially, which represents a decrease of almost $40 \%$. The trend was similar but less spectacular in the case of the $7 \mathrm{~nm}-\mathrm{Co} /$ silica with a decrease of $10 \%$. This decrease was confirmed by ex situ TEM measurements (Fig. S2, ESI $\dagger$ ).

The small particles below $2 \mathrm{~nm}$ not being considered for these calculations, it is worth noting that the real size of the particles should be even lower.

Several hypotheses could be drawn to explain this observation, as illustrated in scheme 1.

Steam treatment could break cobalt-cobalt bonds leading to several smaller particles (Scheme 1a). Such a phenomenon should subsequently enhance the metal dispersion. Without a full partition of large particles into smaller ones, the breaking of cobalt-cobalt bounds could also lead to damaged particles, with crumbled or "eroded" parts more or less in contact (Scheme 1b). The latter hypothesis would then be rather related to an attrition or an erosion process, whereas the former would be related to a classical and ideal redispersion. In both cases, the splitting of crystallites could occur during the cobalt oxidation when Co-Co metallic bonds are broken to form new $\mathrm{Co}-\mathrm{O}$ ionic bonds. Metallic clusters $\mathrm{Co}(-\mathrm{Co})_{n}-\mathrm{Co}$ would then be divided into smaller oxide clusters $\mathrm{CoO}(-\mathrm{CoO})_{n-x}$ and $(\mathrm{CoO})_{x}-\mathrm{CoO}$, the introduced oxygen atom does not bridge all initially bonded cobalt atoms. The proposed crumbling phenomenon could also be viewed as a leaching process where water would not only oxidize cobalt particles but would also extract some cobalt atoms from these particles, leading to smaller and defected crystals.

However, the decrease in coherent domain size does not necessarily mean a decrease in particle size. It could also be assigned to crystalline changes inside the particles without any physical split-up (Scheme 1c). Steam treatment could generate the formation of crystallographic defects such as dislocations, disclinations and stacking faults. New smaller coherent domains with various planar orientations would then appear, leading to different XRD signals as if separated smaller particles were formed.

The decrease in coherent domain size could also be due to the formation of hollow shells of cobalt oxide (Scheme 1d).
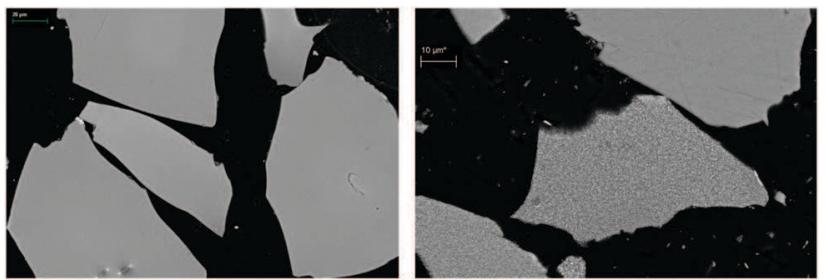

Fig. 4 SEM pictures of the $12 \mathrm{~nm}$-Co/silica catalyst before reduction (left) and after treatment (right).

This phenomenon could be similar to the so-called Kirkendall effect ${ }^{10}$ and was recently proposed by Hauman and coworkers to explain cobalt redispersion during reduction-calcination cycles. ${ }^{8}$ The results described here suggest that such a phenomenon observed during severe oxidation with oxygen could also occur during mild oxidation with water.

SEM experiments showed that water treatment also has an effect on the morphology of the catalysts at the micrometre scale (Fig. 4).

Whereas no or few metal aggregates were observed before treatment with water, the treated samples showed a lot of agglomerates of cobalt. This observation is commonly assigned to a sintering effect. Globally, cobalt particles tend to come closer to form larger clusters, which results in high concentrations of cobalt on some grains whereas some other grains are strongly depleted in cobalt.

This sintering effect which is clearly an agglomeration of particles and not a particle growth seems to be antagonistic to the hypothetical particle break-up supposed to occur on a smaller scale. They may result in fact from two completely different and independent processes, not driven by the same forces. Water was indeed proposed to assist cobalt sintering during oxidation ${ }^{11}$ and even without parallel oxidation. ${ }^{4}$

A second water treatment was carried out over the reduced $12 \mathrm{~nm}-\mathrm{Co} /$ silica catalyst in the presence of $\mathrm{H}_{2}$ with increasing $\mathrm{H}_{2} \mathrm{O} / \mathrm{H}_{2}$ ratio from 2 to 113 . As no change was observed in XRD patterns after around 2 days under a $0.5 \% \mathrm{H}_{2} / 1 \% \mathrm{H}_{2} \mathrm{O} / \mathrm{He}$ flow, the $\mathrm{H}_{2} \mathrm{O} / \mathrm{H}_{2}$ ratio was increased to 10 for 2 days, and then to 32 , 43 and finally 113 . Around 20 hours after the beginning of the last step, cobalt began to oxidise into $\mathrm{CoO}$ and $\mathrm{Co}_{3} \mathrm{O}_{4}$ (Fig. 5).

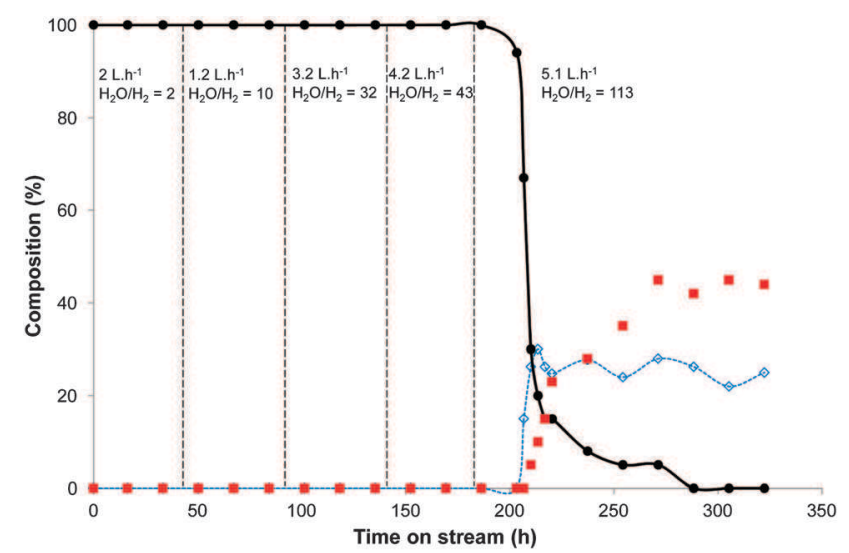

Fig. 5 Composition of the $12 \mathrm{~nm}$-Co/silica catalyst at $230{ }^{\circ} \mathrm{C}$ under a $\mathrm{H}_{2} \mathrm{O} / \mathrm{H}_{2} / \mathrm{He}$ flow with various $\mathrm{H}_{2} \mathrm{O}$ and $\mathrm{H}_{2}$ contents. 
Surprisingly, $\mathrm{Co}_{3} \mathrm{O}_{4}$ appeared almost at the same time as $\mathrm{CoO}$ and not when $\mathrm{CoO}$ reached its maximum as in the former cases without $\mathrm{H}_{2}$. Moreover, although no Co metal was detected anymore after 350 hours on stream, the catalyst still contained a large amount of $\mathrm{CoO}(\sim 25 \%) \cdot \mathrm{Co}_{3} \mathrm{O}_{4}$ formation, with its two different rates, exhibited however a very similar behaviour to that in the case without $\mathrm{H}_{2}$. At the end of the treatment, the catalyst contained only $70 \%$ of cobalt-containing phases detectable using XRD, suggesting that the remaining $30 \%$ is made of particles below $2 \mathrm{~nm}$. Considering the peak assigned to $\mathrm{Co}_{3} \mathrm{O}_{4}$, the average $\mathrm{Co}_{3} \mathrm{O}_{4}$ coherent domain size was $5.8 \mathrm{~nm}$ after treatment, which is a decrease of more than $50 \%$ of the initial size.

The experimental evidence that water can fully oxidize cobalt particles with an oxidation rate dependent on particle size, and also cause important changes in cobalt particle morphology, is very relevant for Fischer-Tropsch research. Two apparently antagonistic effects occur during the steam treatment: on one side crystalline coherent domain size decreases under steam treatment, and on the other side cobalt particles agglomerate to form larger clusters at the surface of the carrier. Oxidation of cobalt was also evidenced in the presence of hydrogen, in cases where the $\mathrm{H}_{2} \mathrm{O} / \mathrm{H}_{2}$ ratio is however higher than 100. In our future work, we plan to extend this investigation to real Fischer-Tropsch systems, with mixtures of water, $\mathrm{CO}$ and $\mathrm{H}_{2}$ at high pressure.

\section{Notes and references}

1 A. R. de la Osa, A. De Lucas, J. Diaz-Maroto, A. Romero, J. L. Valverde and P. Sanchez, Catal. Today, 2012, 187, 173; S. Krishnamoorthy, M. Tu, M. P. Ojeda, D. Pinna and E. Iglesia, J. Catal., 2002, 211, 422.

2 A. M. Saib, D. J. Moodley, I. M. Ciobica, M. M. Hauman, B. H. Sigwebela, C. J. Weststrate, J. W. Niemantsverdriet and J. van de Loosdrecht, Catal. Today, 2010, 154, 271.

3 A. K. Dalai and B. H. Davis, Appl. Catal., A, 2008, 348, 1; M. Sadeqzadeh, S. Chambrey, S. Piché, P. Fongarland, F. Luck, D. Curulla-Ferré, D. Schweich, J. Bousquet and A. Y. Khodakov, Catal. Today, 2013, 215, 52.

4 G. L. Bezemer, T. J. Remans, A. P. van Bavel and A. I. Dugulan, J. Am. Chem. Soc., 2010, 132, 8540.

5 L. Braconnier, E. Landrivon, I. Clémençon, C. Legens, F. Diehl and Y. Schuurman, Catal. Today, 2013, 215, 18; O. Borg, P. Dietzel, A. Spjelkavik, E. Tveten, J. Walmsley, S. Diplas, S. Eri, A. Holmen and E. Rytter, J. Catal., 2008, 259, 161.

6 D. Schanke, A. M. Hilmen, E. Bergene, K. Kinnari, E. Rytter, E. Adnanes and A. Holmen, Catal. Lett., 1995, 34, 269.

7 P. J. van Berge, J. van de Loosdrecht, S. Barradas and A. M. van der Kraan, Catal. Today, 2000, 58, 321.

8 M. M. Hauman, A. Saib, D. J. Moodley, E. du Plessis, M. Claeys and E. van Steen, ChemCatChem, 2012, 4, 1411.

$9 \mathrm{~J}$. van de Loosdrecht, B. Balzhinimaev, J. A. Dalmon, J. W. Niemantsverdriet, S. V. Tsybulya, A. M. Saib, P. J. van Berge and J. L. Visagie, Catal. Today, 2007, 123, 293.

10 C. J. Weststrate, M. M. Hauman, D. J. Moodley, A. M. Saib, E. van Stee and J. W. Niemantsverdriet, Top. Catal., 2011, 54, 811; S. Sadasivan, R. M. Bellabarba and R. P. Tooze, Nanoscale, 2013, 5, 11139.

11 C. J. Bertole, C. A. Mims and G. Kiss, J. Catal., 2002, 210, 84; G. Kiss, C. E. Kliewer, G. J. DeMartin, C. C. Culross and J. E. Baumgartner, J. Catal., 2003, 217, 127. 